\title{
Acute alcohol consumption increases systemic endotoxin bioactivity for days in healthy volunteers - with reduced intestinal barrier loss in female
}

\author{
Ramona Sturm ${ }^{1} \cdot$ Florian Haag $^{1,2} \cdot$ Andrea Janicova $^{2} \cdot$ Baolin Xu $^{2} \cdot$ Jan Tilmann Vollrath ${ }^{1} \cdot$ Katrin Bundkirchen $^{3} \cdot$ \\ Ildiko Rita Dunay ${ }^{4} \cdot$ Claudia Neunaber $^{3} \cdot$ Ingo Marzi $^{1} \cdot$ Borna Relja $^{1,2}$
}

Received: 23 December 2020 / Accepted: 1 April 2021 / Published online: 11 April 2021

(c) The Author(s) 2021

\begin{abstract}
Objective Trauma is the most common cause of death among young adults. Alcohol intoxication plays a significant role as a cause of accidents and as a potent immunomodulator of the post-traumatic response to tissue injury. Polytraumatized patients are frequently at risk to developing infectious complications, which may be aggravated by alcohol-induced immunosuppression. Systemic levels of integral proteins of the gastrointestinal tract such as syndecan-1 or intestinal fatty acid binding proteins (FABP-I) reflect the intestinal barrier function. The exact impact of acute alcohol intoxication on the barrier function and endotoxin bioactivity have not been clarified yet.

Methods 22 healthy volunteers received a precisely defined amount of alcohol (whiskey-cola) every 20 min over a period of $4 \mathrm{~h}$ to reach the calculated blood alcohol concentration (BAC) of $1 \%$. Blood samples were taken before alcohol drinking as a control, and after 2, 4, 6, 24 and $48 \mathrm{~h}$ after beginning with alcohol consumption. In addition, urine samples were collected. Intestinal permeability was determined by serum and urine values of FABP-I, syndecan-1, and soluble (s)CD14 as a marker for the endotoxin translocation via the intestinal barrier by ELISA. BAC was determined.

Results Systemic FABP-I was significantly reduced $2 \mathrm{~h}$ after the onset of alcohol drinking, and remained decreased after $4 \mathrm{~h}$. However, at $6 \mathrm{~h}$, FABP-I significantly elevated compared to previous measurements as well as to controls $(p<0.05)$. Systemic sCD14 was significantly elevated after 6,24 and $48 \mathrm{~h}$ after the onset of alcohol consumption $(p<0.05)$. Systemic FABP-I at $2 \mathrm{~h}$ after drinking significantly correlated with the $\mathrm{SCD} 14$ concentration after $24 \mathrm{~h}$ indicating an enhanced systemic LPS bioactivity. Women showed significantly lower levels of syndecan-1 in serum and urine and urine for all time points until $6 \mathrm{~h}$ and lower FABP-I in the serum after $2 \mathrm{~h}$.

Conclusions Even relative low amounts of alcohol affect the immune system of healthy volunteers, although these changes appear minor in women. A potential damage to the intestinal barrier and presumed enhanced systemic endotoxin bioactivity after acute alcohol consumption is proposed, which represents a continuous immunological challenge for the organism and should be considered for the following days after drinking.
\end{abstract}

Keywords Alcohol $\cdot$ Barrier $\cdot$ FABP $\cdot$ SCD14 $\cdot$ Syndecan- $1 \cdot$ Gender

Borna Relja

Borna.Relja@med.ovgu.de

1 Department of Trauma, Hand and Reconstructive Surgery, Goethe University, Frankfurt, Germany

2 Experimental Radiology, Department of Radiology and Nuclear Medicine, Otto Von Guericke University, Magdeburg, Germany

3 Trauma Department, Hannover Medical School, Hannover, Germany

4 Institute of Inflammation and Neurodegeneration, Otto Von Guericke University, Magdeburg, Germany

\section{Introduction}

Trauma is the leading cause of death among young adults [1, 2], while alcohol use accounts as a major cause of accidents [3]. Among alcohol-related accidents, road traffic injuries are leading, followed by self-harm, interpersonal violence and falls [4]. In Germany, a blood alcohol level of 0.5 per mille is currently permitted in road traffic to prevent drinkdriving [5]. The limit value of 0.5 and 0.8 per mille is frequently used in international comparisons, whereas some countries have no limitation of blood alcohol concentration 
in road traffic [6]. The percentage of alcoholised polytraumatized patients, depending on the study, averages at $>25 \%$ [7]. Patients who initially survive an acute and relevant blood loss, massive tissue injury, or severe traumatic brain injury (TBI) are at high risk for developing post-traumatic imbalance of immunological mediators and immune cells, which may result in inflammatory complications, such as sepsis or multiple organ failure $[8,9]$. In alcoholised polytraumatized patients and alcoholised patients with TBI reduced leukocyte numbers and lowered systemic interleukin (IL)-6 levels [7, 10] indicating an immunosuppressive effect of alcohol have been reported. In this context, damaged intestinal barrier and alcohol use play also decisive roles [11]. The mortality after surgical interventions is increased in severely traumatized patients with acute alcohol intoxication [12]. Studies indicate that acute alcohol intoxication reduces the lipopolysaccharide (LPS)-induced production and release of proinflammatory cytokines and contributes to the development of Toll-like receptor (TLR)4/endotoxin (LPS) tolerances in the murine approach [13].

As a result of damaged enterocytes and thus the intestinal barrier after, e.g., trauma or hypoperfusion (shock), membrane and intracellular proteins are released into the extracellular space and subsequently into the circulation and urine [14]. Furthermore, a damaged intestinal barrier promotes the translocation of damage-associated molecular pattern or bacteria as well. Fatty acid binding proteins (FABPs) are a group of nine partially tissue-specific transport proteins that are localized intracellularly or in the cytoplasmic membrane of different cells [15]. The FABP-I or FABP2 are specifically expressed in enterocytes in the small intestine and occasionally in the colon [16]. Recently, it was shown that FABP-I can be used as an early biomarker for the detection of abdominal injuries in general and specifically for intestinal injuries [17]. Elevated FABP-I level evaluated early after trauma depends on the tissue injury pattern and the presence of shock as well, which is associated with a barrier breakdown [18]. Moreover, the FABP-I in urine and serum may serve as a biomarker for diagnosis of acute mesenteric ischemia $[19,20]$ and can predict mortality and bowel ischemia in patients with septic shock [21]. Syndecan-1 (CD138) as a transmembrane heparan sulphate proteoglycan is expressed predominantly on the basolateral surface of epithelial cells and plasma cells [22]. As a transmembrane protein with extracellular and cytoplasmic domains, syndecane-1 is involved in cell-matrix interactions with cell binding, cell migration and cytoskeletal organization as well as in cell proliferation and cell signalling [23]. In severely injured patients, syndecan-1 has been shown to be elevated in serum associated with subsequent sepsis [24]. CD14 is a surface antigen on monocytes and macrophages and exists in a membrane-bound or soluble form. The soluble (s)CD14 binds LPS and transfers it to the membrane-bound CD14, which serves as a co-receptor for the TLR4-receptor complex. Moreover, sCD14 can transfer the LPS directly to the TLR4-receptor complex [25, 26]. Furthermore, sCD14 seems to neutralize LPS by binding and limiting the amount of monocyte-bound LPS. This may lead to a reduction of the inflammatory response [27]. Soluble CD14 can be used as a biomarker for the LPS bioactivity. Following traumatic injury, intestinal bacteria or bacterial components (e.g., LPS) can translocate into blood circulation where they trigger a proinflammatory response [28].

Chronic alcohol consumption alters the intestinal flora and can further lead to a malfunction and intestinal hyperpermeability [29]. Little is known about the direct impact of acute alcohol consumption on the intestinal barrier, permeability and effects of the immune system, in particular the differences between men and women are unknown.

Since acute alcohol consumption induces immunosuppression and is associated with infectious complications, the aim of the present study was to evaluate the dose- and time-dependent effects of acute alcohol consumption on the intestinal barrier and the immunological changes.

\section{Patients and methods}

\section{Ethics}

This study was performed in accordance with the institutional ethics committee approval (255/14) from the University Hospital of the Goethe University Frankfurt, in accordance with the Declaration of Helsinki and following the Strengthening the Reporting of Observational studies in Epidemiology-guidelines [30]. All healthy volunteers signed the written informed consent form accordance to the ethical standards after detailed explanation of the procedure, effects and objectives of the investigations.

\section{Study population}

Twelve female und ten male healthy volunteers between 18 and 50 years were enrolled. Exclusion criteria were chronic alcohol consumption, pre-existing immunological disorders, chronic inflammatory and explicitly chronic intestinal diseases, HIV and infectious hepatitis or immune-suppressive medication. A detailed alcohol anamnesis was taken, including the standardized "Alcohol Use Disorders Identification Test" to exclude regular and chronic alcohol consumption. Furthermore, hepatic and renal insufficiencies were previously excluded by blood examination.

Healthy volunteers, who received a standardized lunch 1 hour before the experiment, drank an individually calculated amount of alcohol, which should lead to a blood alcohol level of $1 \%$ after the end of consumption. The calculation 
was made according to the modified Widmark equation depending on age, sex, height and weight. Every $20 \mathrm{~min}$ over $4 \mathrm{~h}$ equal mixed drinks consisting of whisky (Tennessee Whiskey Jack Daniels, 40\%) and cola (Coca-Cola) in a mixing ratio of 1:2 were drunk. Subsequently, a 2-h monitoring phase without further alcohol consumption followed. All study participants drank 11 of water during the first $6 \mathrm{~h}$ of the experiments. The experimental design is shown in Fig. 1.

\section{Blood sampling}

Blood samples were taken before alcohol consumption (T0) as a control and after $2 \mathrm{~h} \mathrm{(T2),} 4 \mathrm{~h}$ (T4), $6 \mathrm{~h}$ (T6), $24 \mathrm{~h}$ (T24) and $48 \mathrm{~h}$ (T48) after beginning of alcohol consumption. The blood was withdrawn in serum-gel tubes (Sarstedt, Nürmbrecht, Germany) and centrifuged immediately after collection at $2,000 \times g$ for $15 \mathrm{~min}$ at $4{ }^{\circ} \mathrm{C}$. The supernatant was stored at $-80^{\circ} \mathrm{C}$ until analysis. Furthermore, the serum alcohol concentration was determined by the clinical laboratory.

\section{Urine sampling}

Before starting the experiment, urine was delivered, centrifuged and frozen at $-80^{\circ} \mathrm{C}$ (at T0). From T0 to T2, as well as from $\mathrm{T} 2$ to $\mathrm{T} 4$ and from $\mathrm{T} 4$ to $\mathrm{T} 6$, the urine was collected in separate containers, centrifuged at $2,000 \times g$ for $15 \mathrm{~min}$ at $4{ }^{\circ} \mathrm{C}$ and stored at $-80^{\circ} \mathrm{C}$.

\section{Measurement of FABP-I, syndecan-1 and SCD14}

Both serum and urine samples were thawed for direct use and measurement of FABP-I, syndecan-1 and sCD14. According to manufacturer's instructions, Human FABP2/I-FABP DuoSet enzyme-linked immunosorbent assay (ELISA) (R and D Systems, Minneapolis, USA, \# DY3078) was used to measure intestinal FABP and Syndecan-1 DuoSet ELISA (R and D Systems, Minneapolis, USA, \#DY2780) was used to measure syndecan-1 concentrations in serum and urine. Human CD14 DuoSet ELISA (R\&D Systems, Minneapolis, USA, \#DY383) was utilized according to manufacturer`s instructions to measure $\mathrm{sCD} 14$ concentrations in serum and urine.

\section{Statistical analysis}

GraphPad Prism 6.0 software (GraphPad Software Inc. San Diego, CA, USA) was used to perform the statistical analysis. Data are given as mean \pm standard error of the mean (SEM). The Kruskal-Wallis test with a Dunn's post hoc test was applied to compare the differences between the groups. Spearman's correlation coefficient was calculated to determine correlations. A $p$ value below 0.05 was considered statistically significant.

\section{Results}

\section{Study population}

Twenty-two healthy volunteers were enrolled in this study. The mean age was $25 \pm 4$ years. 10 out of 22 patients were male $(45.45 \%)$. The experimental design is shown in Fig. 1.

\section{Blood alcohol concentration}

All volunteers had no measurable blood alcohol concentration at the beginning of the experiment. At T2 the legally permissible alcohol level $(0.5 \% o)$ for the road traffic had nearly been reached. The BAC increased significantly at $\mathrm{T} 2$ to $0.46 \pm 0.02 \%$ o compared to T0 ( $p<0.05$, Fig. $2 \mathrm{a}$ ). After $\mathrm{T} 4$, the aim concentration with $1.11 \pm 0.05 \%$ o was reached (Fig. 2a). $2 \mathrm{~h}$ after the end of alcohol consumption (T6), the BAC dropped to $0.83 \pm 0.06 \%$ o still being significantly enhanced compared to T0 ( $p<0.05$, Fig. 2a). At T24 and T48, no BAC was detectable. There were no significant gender-specific differences among the BAC levels (Fig. 2b).
Fig. 1 Experimental design. Before alcohol (ethanol, EtOH) drinking (T0), $2 \mathrm{~h}$ (T2), $4 \mathrm{~h}$ (T4), $6 \mathrm{~h}$ (T6), $24 \mathrm{~h}$ (T24) and $48 \mathrm{~h}$ (T48) after start of alcohol consumption sampling of either blood (B) or urine (U) from healthy volunteers was performed. The aim blood alcohol concentration of one per mille (1\%o) was reached at T4

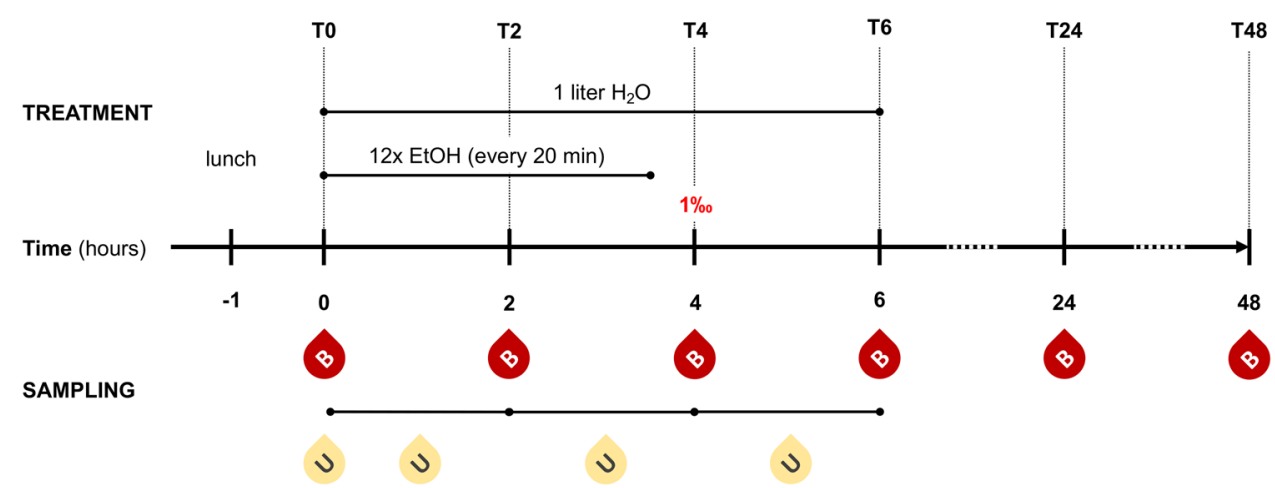


$\mathbf{A}$

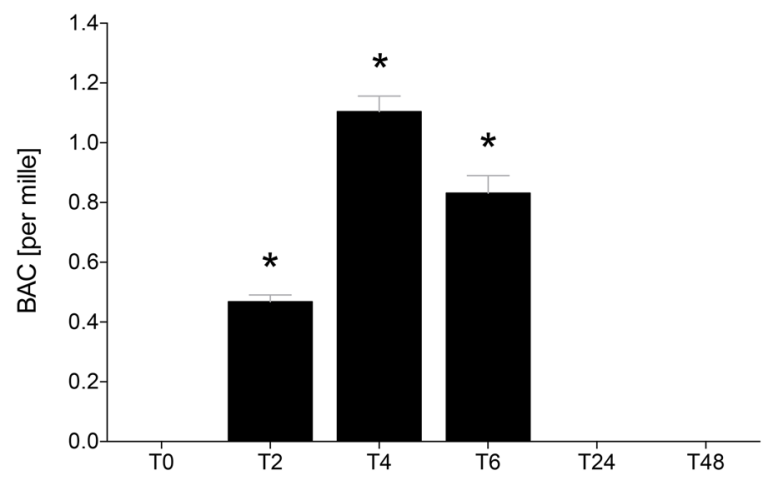

B

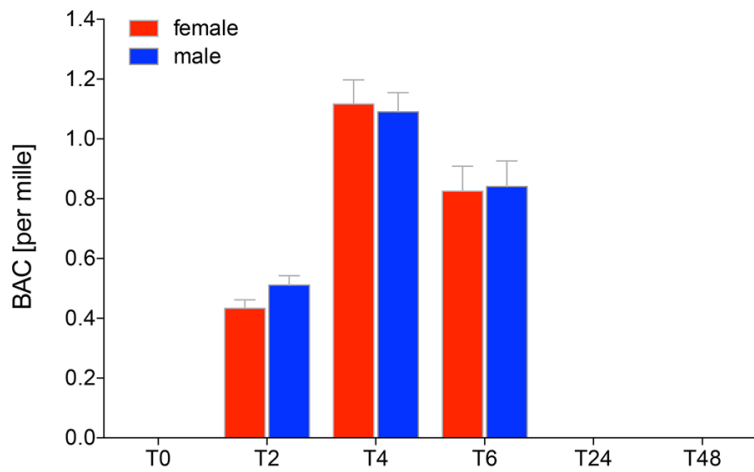

Fig. 2 Blood alcohol concentration (BAC) in sera of healthy volunteers before, during and after alcohol drinking. Mean BAC as per mille determined in sera from healthy volunteers before (T0), $2 \mathrm{~h}$ (T2), $4 \mathrm{~h}$ (T4), 6 h (T6), 24 h (T24) and 48 h (T48) after start of alcohol consumption are given. a Data from all healthy volunteers $(n=22)$, and $\mathbf{b}$ gender-specific results are shown (female: $n=12$ and male: $n=10)$. The data are presented as mean \pm standard error of the mean. $* p<0.05$ vs. T0

\section{FABP-I in serum and urine}

Before alcohol intake, the intestinal FABP in serum of healthy volunteers was $441.30 \pm 44.15 \mathrm{pg} / \mathrm{ml}$ (Fig. 3a). At $\mathrm{T} 2$ and $\mathrm{T} 4$ after beginning of acute alcohol consumption, the FABP-I in serum was significantly reduced compared to T0 (T2: $355.90 \pm 35.44$ or T4: $338.50 \pm 38.40$ vs. T0: $441.30 \pm 44.15 \mathrm{pg} / \mathrm{ml}, p<0.05$, Fig. 3a). At T6, the intestinal FABP was significantly increased compared to T0 (T6: $552.20 \pm 56.83$ vs. T0: $441.30 \pm 44.15 \mathrm{pg} / \mathrm{ml}, p<0.05$, Fig. 3a). The levels of intestinal FABP remained elevated for the next 2 days at T24 and T48, however, no statistical difference was found. Gender-specific analyses showed a significant difference between men and women at $\mathrm{T} 2$ with higher levels in men ( $p<0.05$, Fig. 3b).

The urinary level of $16.24 \pm 3.90 \mathrm{pg} / \mathrm{ml}$ of intestinal FABP has been detected in healthy volunteers before alcohol consumption (Fig. 3c). In the collected urine at T4, the FABP-I concentration was significantly reduced compared to $\mathrm{T} 0$ (T4: $5.06 \pm 3.40$ vs. T0: $16.24 \pm 3.90 \mathrm{pg} / \mathrm{ml}, p<0.05$, Fig. $3 \mathrm{c})$. At T6, the FABP-I levels increased to normal values (Fig. 3c).
The gender-specific analyses have shown no differences between men and women over the observational time course (Fig. 3d).

\section{Syndecan-1 in serum and urine}

Beside in healthy volunteers, there were no significant differences among the serum concentrations of syndecan- 1 during the observational period compared to normal values detected at T0 before alcohol administration $(2.15 \pm 0.56 \mathrm{ng} / \mathrm{ml}$, Fig. 4a). However, the gender-specific values were significantly higher in men compared to women during the observational period between time points T0 and T6 ( $p<0.05$, Fig. $4 \mathrm{~b})$.

The urine levels of syndecan- 1 before alcohol consumption at T0 were at $3.39 \pm 0.24 \mathrm{ng} / \mathrm{ml}$ (Fig. $4 \mathrm{c}$ ). In the collected urine at $\mathrm{T} 4$, the syndecan- 1 concentration was significantly reduced compared to T0 (T4: $2.33 \pm 0.21$ vs. T0: $3.39 \pm 0.24 \mathrm{ng} / \mathrm{ml}, p<0.05$, Fig. $4 \mathrm{c}$ ). After alcohol consumption, the syndecan- 1 values in the urine increased again to levels comparable with T0 controls (Fig. 4c). The concentrations of syndecan- 1 were significantly reduced in women compared with men at all evaluated time points $(p<0.05$, Fig. 4d).

\section{Soluble CD14 in serum}

Before alcohol administration, the serum level of sCD14 in healthy volunteers was $3432.00 \pm 258.40 \mathrm{ng} / \mathrm{ml}$ (Fig. 5a). At $\mathrm{T} 2$ and $\mathrm{T} 4$, the sCD14 in serum increased continuously compared to T0. At T6, the sCD14 was significantly increased compared to T0 (T6: $4388.00 \pm 398.50$ vs. T0: $3432.00 \pm 258.40 \mathrm{ng} / \mathrm{ml}, p<0.05$, Fig. 5a). The levels of sCD14 remained elevated at $\mathrm{T} 24$ and $\mathrm{T} 48$ compared to $\mathrm{T} 0$ (T24: $5363.00 \pm 312.50$ or T48: $5300.00 \pm 324.20$ vs. T0: $3432.00 \pm 258.40 \mathrm{ng} / \mathrm{ml}, p<0.05$, Fig. 5a). The gender-specific analyses have shown significant higher levels of sCD14 in women compared to men at T0 (Fig. 5b). In the further time course of alcohol intake there were no significant gender-specific differences (Fig. 5b).

\section{Correlation of FABP-I and SCD14 in serum}

The Spearman's rank correlation showed a significant correlation for systemic FABP-I levels at T2 and SCD14 at T24 ( $p<0.05$, Spearman $r=0.8182$, Fig. 6). No further correlations were found for other parameters or time points.

\section{Discussion}

The immunological response to acute alcohol intoxication co-determines the clinical course of patients after severe injuries and/or surgical interventions. The existing studies 
A

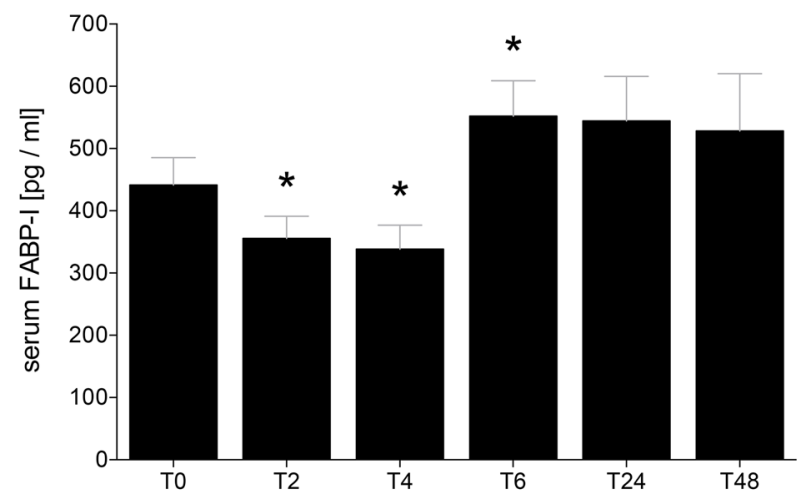

B

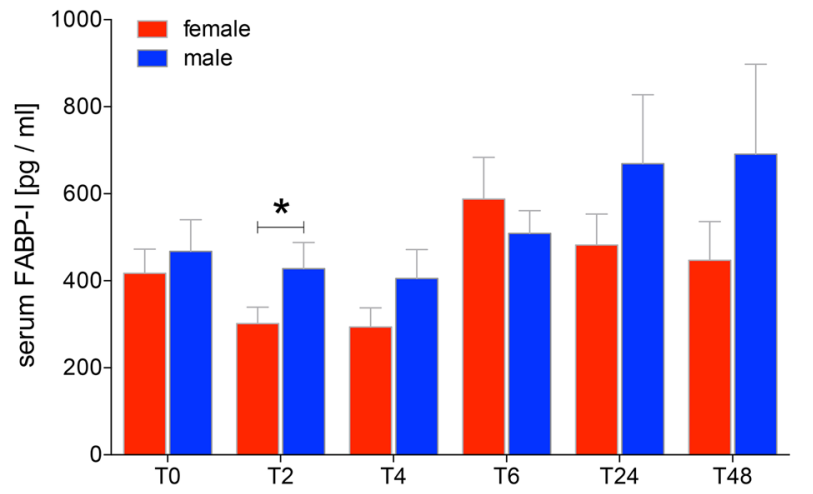

C

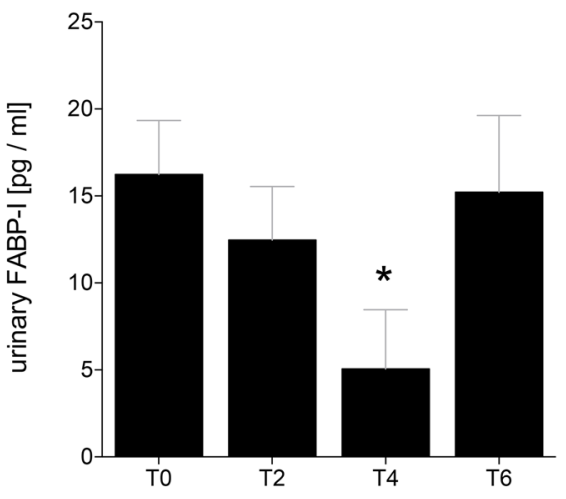

D

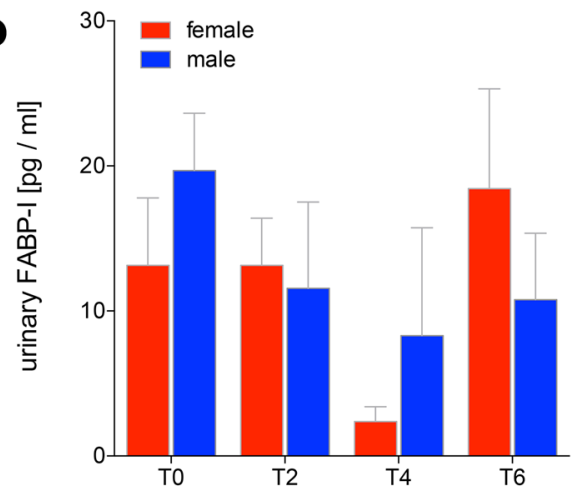

Fig. 3 Levels of intestinal fatty-acid binding protein (FABP-I) in sera and urine of healthy volunteers before, during and after alcohol consumption. Mean values of intestinal FABP in $\mathrm{pg} / \mathrm{ml}$ determined in sera $(\mathbf{a}, \mathbf{b})$ or urine $(\mathbf{c}, \mathbf{d})$ from healthy volunteers before (T0), $2 \mathrm{~h}$ (T2), $4 \mathrm{~h}$ (T4), and $6 \mathrm{~h}$ (T6) after start of alcohol consumption are given. $24 \mathrm{~h}$ (T24) and $48 \mathrm{~h}$ (T48) after experimentation, FABP-I was determined in sera as well. Urine samples were analysed before alco- hol consumption (T0), collected and pooled over the first $2 \mathrm{~h}$ (T2), from T2 until the following $2 \mathrm{~h}$ (T4), and from T4 until T6 (T6). a, c Data from all healthy volunteers $(n=22)$ are shown, and $\mathbf{b}, \mathbf{d}$ genderspecific results are shown (female: $n=12$ and male: $n=10$ ). The data are presented as mean \pm standard error of the mean. ${ }^{*} p<0.05$ vs. T0 or in B vs. indicated groups

hours to simulate the physiological conditions and drinking behavior. The study participants reached already at $2 \mathrm{~h}$ after drinking a legally permitted alcohol level (Fig. 2a).

Numerous studies have shown that FABP-I can be used as a non-invasive marker for intestinal diseases like celiac disease [31] or intestinal ischemia [32] and also for intestinal damage in severely injured patients [17]. In the present study, the FABP-I concentration decreased significantly very early after alcohol consumption. However, serum FABPI concentrations were significantly elevated after $6 \mathrm{~h}$ and remains enhanced over the next 2 days (Fig. 3a). The primary decrease of the FABP concentration in serum may be caused by an initially delayed transport and resorption of the alcohol with a full stomach and reduced motility. This decrease in the FABP concentration was mainly present in women, which in turn significantly influence the overall result. The absence of a significant differences among later time points T24 and T48 may be caused by the lower number of included healthy volunteers since several participants did not show up for further blood withdrawals. A similar decrease in urine FABP-I concentration was detected at T4 
$\mathbf{A}$

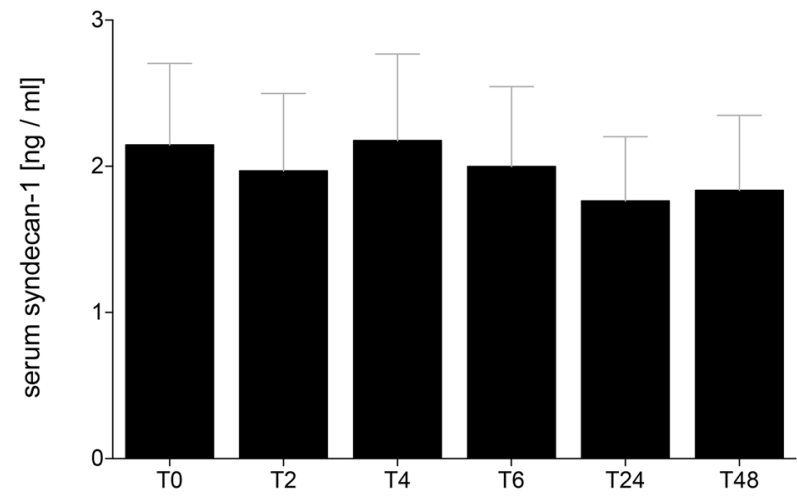

B

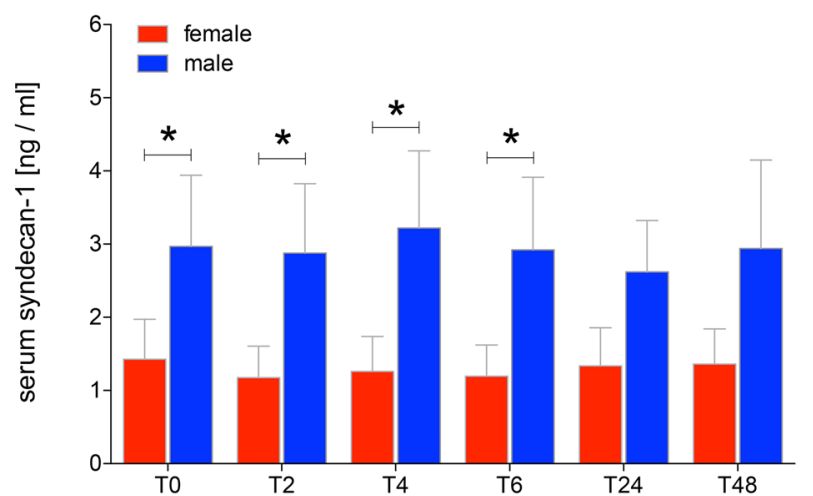

C

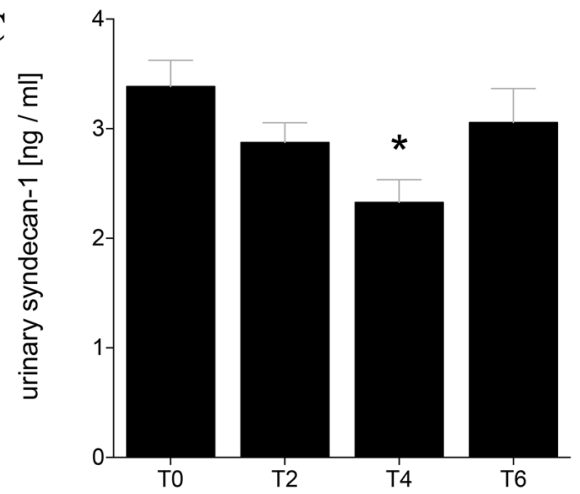

D

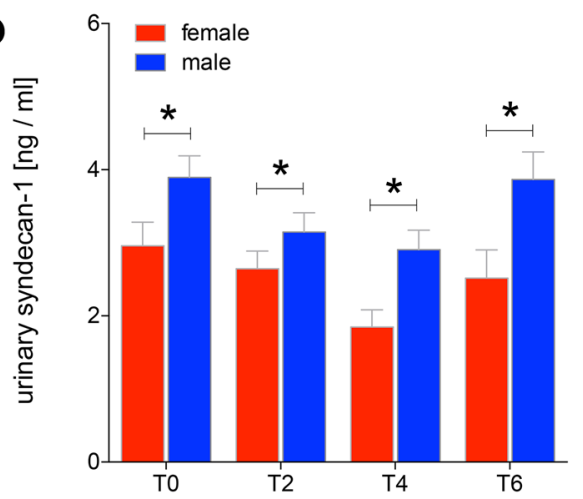

Fig. 4 Syndecan-1 levels in sera and urine of healthy volunteers before, during and after alcohol consumption. Mean values of syndecan-1 in $\mathrm{ng} / \mathrm{ml}$ determined in sera $(\mathbf{a}, \mathbf{b})$ or urine $(\mathbf{c}, \mathbf{d})$ from healthy volunteers before (T0), $2 \mathrm{~h}$ (T2), $4 \mathrm{~h}$ (T4), and $6 \mathrm{~h}$ (T6) after start of alcohol consumption are given. $24 \mathrm{~h}$ (T24) and $48 \mathrm{~h}$ (T48) after experimentation, syndecan-1 was determined in sera as well. Urine samples were analysed before alcohol consumption (T0), col-

(Fig. 3c). Serum values indicate damage to the intestinal barrier in the early phase after alcohol intoxication.

Interestingly, it has been shown that severely injured women have a better outcome than men with comparable injury patterns [33]. The underlying mechanism is still unexplained. Hundscheid et al. demonstrated that the small intestine of female is more resistant to reperfusion-related intestinal damage than that of men [34]. Our data show lower serum FABP-I concentration $2 \mathrm{~h}$ after alcohol consumption in women, potentially underlining the above-mentioned study results (Fig. 3b). Furthermore, women showed lower syndecan-1 concentrations in both blood and urine before, during and $2 \mathrm{~h}$ after alcohol consumption as well (Fig. 4b, d). In addition, higher levels of sCD14 in women under normal conditions compared to men were found (Fig. 5b). In absolute terms, women consumed less volume of alcohol compared to men. However, calculating the amount of alcohol, both height and weight were included resulting in a comparable BAC without differences between both gender.

In non-cirrhotic alcoholics, the intestinal barrier breakdown and systemic LPS were observed and 2 weeks after lected and pooled over the first $2 \mathrm{~h}$ (T2), from $\mathrm{T} 2$ until the following $2 \mathrm{~h}$ (T4), and from T4 until T6 (T6). a, c Data from all healthy volunteers $(n=22)$ are shown, and $\mathbf{b}$, $\mathbf{d}$ gender-specific results are shown (female: $n=12$ and male: $n=10$ ). The data are presented as mean \pm standard error of the mean. ${ }^{*} p<0.05$ vs. T0 or in $\mathbf{b}$, $\mathbf{d}$ vs. indicated groups

admission to a detoxification program, the patients still exhibited an increase of proinflammatory cytokines and persistent low-grade-inflammation of intestine [35]. This suggests that alcohol in both acute and chronic settings damages the intestinal barrier and results in increased LPS bioactivity over the period of acute consumption. Afshar et al. have shown an increase in the LPS-induced proinflammatory TNF- $\alpha$ levels 20 min after a single alcohol shot, while after 2 and $5 \mathrm{~h}$ an enhanced anti-inflammatory effect due to reduced IL-1 $\beta$ response upon LPS-stimulation appeared [36]. Similarly, Bala et al. administered single vodka mixed drink to healthy volunteers showing a higher BAC in women compared to men. Few hours after alcohol intake, the serum concentration of endotoxin did not change, whereas SCD14 increased significantly after $24 \mathrm{~h}$ being in line with our findings [37]. Interestingly, men who fastened 1 day and subsequently consumed a single drink exhibited a significant decrease of medium BAC value $(0.07 \%)$. On the other hand, de Jong et al. showed, the intestinal FABP increased in serum right from the start of the experiment but there was no change in sCD14 levels [38]. The different results may be 
A

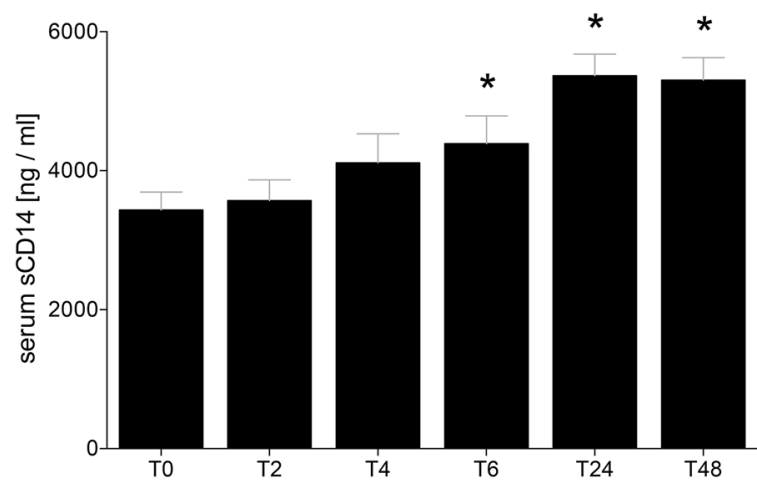

B

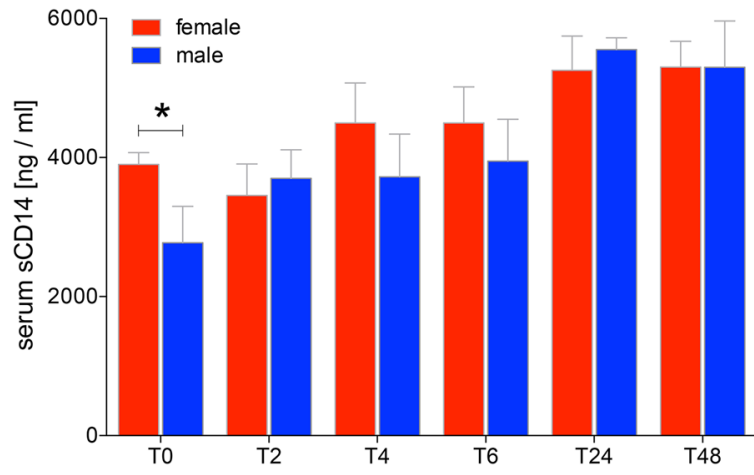

Fig. 5 Soluble (s)CD14 in sera before, during and after alcohol consumption. Mean sCD14 values determined were determined in $\mathrm{ng} / \mathrm{ml}$ in sera from healthy volunteers before (T0), $2 \mathrm{~h}$ (T2), $4 \mathrm{~h}$ (T4), $6 \mathrm{~h}$ (T6), $24 \mathrm{~h}$ (T24) and $48 \mathrm{~h}$ (T48) after start of alcohol consumption. a Data from all healthy volunteers $(n=22)$, and $\mathbf{b}$ gender-specific results are shown (female: $n=12$ and male: $n=10$ ). The data are presented as mean \pm standard error of the mean. ${ }^{*} p<0.05$ vs. T0 or in $\mathbf{b}$ vs. indicated groups

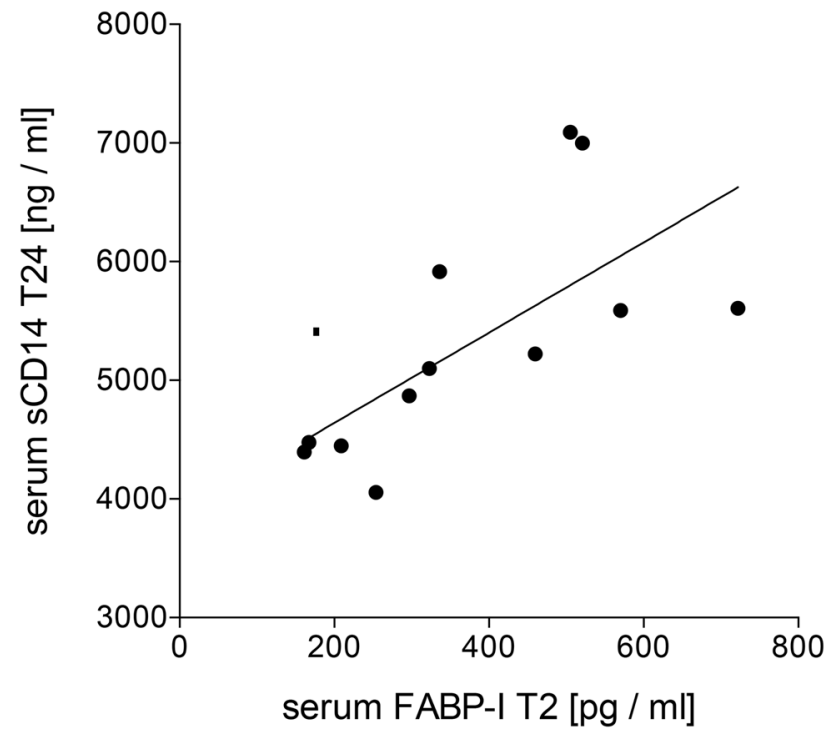

Fig. 6 Spearman analysis of the correlation between the systemic soluble (s)CD14 and intestinal fatty-acid binding protein (FABP-I) after acute alcohol consumption. Positive correlation with a Spearman $r=0.8182$ between the circulatory FABP-I at $2 \mathrm{~h}$ (T2) and sCD14 at $24 \mathrm{~h}$ after beginning of the alcohol intake is shown $(p<0.05, n=12)$ based on the differences in the study design. Interestingly, we found a significant decrease in intestinal FABP concentration in serum early after acute alcohol consumption. However, the immediate high-fat nutritional intake before alcohol consumption could have contributed to this result since Lubbers et al. demonstrated that a continuous high-protein and high-fat diet exerts anti-inflammatory effects [39]. We demonstrated that alcohol intake increased serum sCD14 significantly at $\mathrm{T} 6$ and remained significantly elevated over the next 2 days at $\mathrm{T} 24$ and $\mathrm{T} 48$.

SolubleCD14 mediates a complex function with binding of LPS and transfer to the TLR4-receptor complex with subsequent proinflammatory immune response [25], but also due to the possibility of neutralizing LPS [27]. Therefore, $\mathrm{sCD} 14$ may serve as a biomarker for LPS bioactivity. The significant increase of FABP-I in serum following acute alcohol consumption suggests a possible damage to the intestinal barrier. This might lead to a potential translocation of pathogen-associated molecular pattern and endotoxins. This may be caused by increased BAC with persisting alcohol consumption and thus also a prolonged direct impact of alcohol itself on the intestine wall. In comparison, Lambert et al. detected systemic endotoxins and TNF-alpha in a mouse study after the animals were administered LPS by intragastric gavage after administration of alcohol [40]. However, it should be noted that the immediate origin of measured sCD14 is not clear, so in addition to shedding from leucocytes, synthesis by hepatocytes is possible, and here sCD14 also occurs as an acute phase protein [41]. Under common circumstances multiple drinks during the evening are usual, and, therefore, our study setting constitutes a realistic scenario providing evidence for a disturbed intestinal barrier function upon drinking. The time line of the barrier loss upon drinking and immune-suppressive effects of alcohol on the other hand must be evaluated in further studies.

\section{Strengths and limitations}

The investigation of the acute alcohol effects on the intestinal barrier and systemic immune response was conducted in a prospective study of healthy volunteers previously examined clinically and by laboratory chemistry. There was an almost balanced gender distribution with no differences in the blood alcohol concentration between the sexes. However, when considering the individual sexes, the divided cohorts into male and female were not particularly large and not all healthy volunteers appeared for the follow-up measurements at t24 and t48. Furthermore, concomitant effects due to the previous food intake and the use of a mixed drink with cola cannot be excluded. Although our study design is intended to illustrate a realistic scenario with food and several drinks taken over the evening. 


\section{Conclusion}

We investigated the time-dependent effect of acute alcohol consumption of one per mille on the intestinal barrier in 22 healthy volunteers. $6 \mathrm{~h}$ after the onset of alcohol consumption, a significant increase of FABP-I was detectable in serum, suggesting damage to the intestinal barrier after acute alcohol consumption. Furthermore, sCD14 was shown to be significantly elevated at T6, T24 and T48. This suggests an increased LPS bioactivity due to the influence of acute alcohol drinking potentially causing damage of the intestinal barrier, which is still present 2 days after alcohol ingestion. Interestingly, gender-specific effects were observed although the same BAC was present. Females exhibit significantly lower syndecan-1 levels and significantly higher serum sCD14 levels in blood before alcohol intake.

After acute alcohol consumption a potential damage to the intestinal barrier and presumed enhanced systemic endotoxin bioactivity is suggested, which may represent a continuous immunological challenge to the organism and which should be considered for the following days after drinking.

Acknowledgements We thank Katrin Jurida, Kerstin Kontradowitz, and Elsie Oppermann for outstanding technical assistance.

Author contributions BR designed the study, obtained the ethical approval, performed statistical analyses and revised the manuscript. RS performed the experiments, the statistical analyses and wrote the original draft. $\mathrm{FH}, \mathrm{AJ}$ and $\mathrm{BX}$ collected the samples and carried out the analyses. JTV and KB revised the manuscript. IRD, CN and IM contributed intellectually to the completion of the study.

Funding Open Access funding enabled and organized by Projekt DEAL. The study was supported by grants from the Deutsche Forschungsgemeinschaft (grant nos. DFG RE 3304/5-1, DFG RE 3304/9-1, DFG NE 1932/1-3 and Nachwuchsförderung AO Trauma Deutschland (R.S.)

\section{Declarations}

Conflict of interest The authors declare no conflict of interest.

Open Access This article is licensed under a Creative Commons Attribution 4.0 International License, which permits use, sharing, adaptation, distribution and reproduction in any medium or format, as long as you give appropriate credit to the original author(s) and the source, provide a link to the Creative Commons licence, and indicate if changes were made. The images or other third party material in this article are included in the article's Creative Commons licence, unless indicated otherwise in a credit line to the material. If material is not included in the article's Creative Commons licence and your intended use is not permitted by statutory regulation or exceeds the permitted use, you will need to obtain permission directly from the copyright holder. To view a copy of this licence, visit http://creativecommons.org/licenses/by/4.0/.

\section{References}

1. NIS LeaT-DdS. 2017. Trauma Register DGU Jahresbericht 2017.

2. Sakran JV, Greer SE, Werlin E, McCunn M. Care of the injured worldwide: trauma still the neglected disease of modern society. Scand J Trauma Resusc Emerg Med. 2012;20:64.

3. Green RS, Kureshi N, Erdogan M. Legal consequences for alcohol-impaired drivers injured in motor vehicle collisions: a systematic review. Accid Anal Prev. 2015;80:106-16.

4. <Global status report on alcohol and health2018.pdf >

5. Straßenverkehrsgesetz(StVG) §24a 0 P-G.

6. Organisation WH. 2018. Legal BAC limits by country.

7. Relja B, Menke J, Wagner N, Auner B, Voth M, Nau C, Marzi I. Effects of positive blood alcohol concentration on outcome and systemic interleukin- 6 in major trauma patients. Injury. 2016;47:640-5.

8. Wutzler S, Lustenberger T, Relja B, Lehnert M, Marzi I. Pathophysiology of multiple trauma: intensive care medicine and timing of treatment. Chirurg. 2013;84:753-8.

9. Huber-Lang M, Gebhard F, Schmidt CQ, Palmer A, Denk S, Wiegner R. Complement therapeutic strategies in trauma, hemorrhagic shock and systemic inflammation - closing Pandora's box? Semin Immunol. 2016;28:278-84.

10. Wagner N, Akbarpour A, Mors K, Voth M, Stormann P, Auner B, Lehnert M, Marzi I, Relja B. Alcohol intoxication reduces systemic interleukin-6 levels and leukocyte counts after severe TBI compared with not intoxicated TBI patients. Shock. 2016;46:261-9.

11. Relja B, Hohn C, Bormann F, Seyboth K, Henrich D, Marzi I, Lehnert M. Acute alcohol intoxication reduces mortality, inflammatory responses and hepatic injury after haemorrhage and resuscitation in vivo. Br J Pharmacol. 2012;165:1188-99.

12. Jurkovich GJ, Rivara FP, Gurney JG, Fligner C, Ries R, Mueller BA, Copass M. The effect of acute alcohol intoxication and chronic alcohol abuse on outcome from trauma. JAMA. 1993;270:51-6.

13. Bala S, Tang A, Catalano D, Petrasek J, Taha O, Kodys K, Szabo $\mathrm{G}$. Induction of Bcl-3 by acute binge alcohol results in toll-like receptor 4/LPS tolerance. J Leukoc Biol. 2012;92:611-20.

14. Groschwitz KR, Hogan SP. Intestinal barrier function: molecular regulation and disease pathogenesis. J Allergy Clin Immunol. 2009;124:3-20 (quiz 1-2).

15. Glatz JF, van der Vusse GJ. Cellular fatty acid-binding proteins: their function and physiological significance. Prog Lipid Res. 1996;35:243-82.

16. Pelsers MM, Namiot Z, Kisielewski W, Namiot A, Januszkiewicz M, Hermens WT, Glatz JF. Intestinal-type and liver-type fatty acid-binding protein in the intestine. Tissue distribution and clinical utility. Clin Biochem. 2003;36:529-35.

17. Voth M, Duchene M, Auner B, Lustenberger T, Relja B, Marzi I. I-FABP is a novel marker for the detection of intestinal injury in severely injured trauma patients. World J Surg. 2017;41:3120-7.

18. de Haan JJ, Lubbers T, Derikx JP, Relja B, Henrich D, Greve JW, Marzi I, Buurman WA. Rapid development of intestinal cell damage following severe trauma: a prospective observational cohort study. Crit Care. 2009;13:R86.

19. Salim SY, Young PY, Churchill TA, Khadaroo RG. Urine intestinal fatty acid-binding protein predicts acute mesenteric ischemia in patients. J Surg Res. 2017;209:258-65.

20. Cronk DR, Houseworth TP, Cuadrado DG, Herbert GS, McNutt $\mathrm{PM}$, Azarow KS. Intestinal fatty acid binding protein (I-FABP) for the detection of strangulated mechanical small bowel obstruction. Curr Surg. 2006;63:322-5. 
21. Sekino M, Funaoka H, Sato S, Okada K, Inoue H, Yano R, Matsumoto S, Ichinomiya T, Higashijima U, Matsumoto S, Hara T. Intestinal fatty acid-binding protein level as a predictor of 28-day mortality and bowel ischemia in patients with septic shock: a preliminary study. J Crit Care. 2017;42:92-100.

22. Rapraeger A, Jalkanen M, Bernfield M. Cell surface proteoglycan associates with the cytoskeleton at the basolateral cell surface of mouse mammary epithelial cells. J Cell Biol. 1986;103:2683-96.

23. Bartlett AH, Hayashida K, Park PW. Molecular and cellular mechanisms of syndecans in tissue injury and inflammation. Mol Cells. 2007;24:153-66.

24. Wei S, Gonzalez Rodriguez E, Chang R, Holcomb JB, Kao LS, Wade CE, Group PS. Elevated syndecan-1 after trauma and risk of sepsis: a secondary analysis of patients from the pragmatic, randomized optimal platelet and plasma ratios (PROPPR) trial. J Am Coll Surg. 2018;227:587-95.

25. Hailman E, Vasselon T, Kelley M, Busse LA, Hu MC, Lichenstein HS, Detmers PA, Wright SD. Stimulation of macrophages and neutrophils by complexes of lipopolysaccharide and soluble CD14. J Immunol. 1996;156:4384-90.

26. Frey EA, Miller DS, Jahr TG, Sundan A, Bazil V, Espevik T, Finlay BB, Wright SD. Soluble CD14 participates in the response of cells to lipopolysaccharide. J Exp Med. 1992;176:1665-71.

27. Jacque B, Stephan K, Smirnova I, Kim B, Gilling D, Poltorak A. Mice expressing high levels of soluble CD14 retain LPS in the circulation and are resistant to LPS-induced lethality. Eur J Immunol. 2006;36:3007-16.

28. Hacker G, Redecke V, Hacker H. Activation of the immune system by bacterial CpG-DNA. Immunology. 2002;105:245-51.

29. Meroni M, Longo M, Dongiovanni P. Alcohol or gut microbiota: who is the guilty? Int J Mol Sci. 2019;20:4568.

30. von Elm E, Altman DG, Egger M, Pocock SJ, Gotzsche PC, Vandenbroucke JP, Initiative $\mathrm{S}$. The strengthening the reporting of observational studies in epidemiology (STROBE) statement: guidelines for reporting observational studies. J Clin Epidemiol. 2008;61:344-9.

31. Oldenburger IB, Wolters VM, Kardol-Hoefnagel T, Houwen RHJ, Otten HG. Serum intestinal fatty acid-binding protein in the noninvasive diagnosis of celiac disease. APMIS. 2018;126:186-90.

32. Montagnana M, Danese E, Lippi G. Biochemical markers of acute intestinal ischemia: possibilities and limitations. Ann Transl Med. 2018;6:341.

33. Frink M, Pape HC, van Griensven M, Krettek C, Chaudry IH, Hildebrand F. Influence of sex and age on mods and cytokines after multiple injuries. Shock. 2007;27:151-6.

34. Hundscheid IHR, Schellekens D, Grootjans J, Derikx JPM, Buurman WA, Dejong CHC, Lenaerts K. Females are more resistant to ischemia-reperfusion-induced intestinal injury than males: a human study. Ann Surg. 2018;272(6):1070-9.

35. Leclercq S, Cani PD, Neyrinck AM, Starkel P, Jamar F, Mikolajczak M, Delzenne NM, de Timary P. Role of intestinal permeability and inflammation in the biological and behavioral control of alcohol-dependent subjects. Brain Behav Immun. 2012;26:911-8.

36. Afshar M, Richards S, Mann D, Cross A, Smith GB, Netzer G, Kovacs E, Hasday J. Acute immunomodulatory effects of binge alcohol ingestion. Alcohol. 2015;49:57-64.

37. Bala S, Marcos M, Gattu A, Catalano D, Szabo G. Acute binge drinking increases serum endotoxin and bacterial DNA levels in healthy individuals. PLoS ONE. 2014;9:e96864.

38. de Jong WJ, Cleveringa AM, Greijdanus B, Meyer P, Heineman E, Hulscher JB. The effect of acute alcohol intoxication on gut wall integrity in healthy male volunteers; a randomized controlled trial. Alcohol. 2015;49:65-70.

39. Lubbers T, Kox M, de Haan JJ, Greve JW, Pompe JC, Ramakers BP, Pickkers P, Buurman WA. Continuous administration of enteral lipid- and protein-rich nutrition limits inflammation in a human endotoxemia model. Crit Care Med. 2013;41:1258-65.

40. Lambert JC, Zhou Z, Wang L, Song Z, McClain CJ, Kang YJ. Prevention of alterations in intestinal permeability is involved in zinc inhibition of acute ethanol-induced liver damage in mice. J Pharmacol Exp Ther. 2003;305:880-6.

41. Pan Z, Zhou L, Hetherington CJ, Zhang D-E. Hepatocytes contribute to soluble $\mathrm{CD} 14$ production, and $\mathrm{CD} 14$ expression is differentially regulated in hepatocytes and monocytes. J Biol Chem. 2000;275:36430-5. 